\title{
Dimensões formativas decorrentes da congada em Lambari/MG: entre experiência, saberes e ancestralidade
}

\section{Formative dimensions arising from congada in Lambari/MG: between experience, knowledge and ancestrality}

\author{
Aline Guerra da Costa $^{1}$ \\ Fabio Pinto Gonçalves dos Reis ${ }^{2}$ \\ Lívia Nascimento Monteiro ${ }^{3}$ \\ Kleber Tüxen Carneiro ${ }^{4}$
}

\section{Resumo}

Trata-se de um artigo cujo teor retrata uma investigação científica, relativa aos aspectos formativos (relação entre ensino e aprendizado) contidos na Congada. No plano epistemológico, situamo-la como um fenômeno histórico, originalmente de matriz africana (banta, marcada pelo apreço à ancestralidade e o sagrado), que sofreu ressignificações ao se entremear com a cultura brasileira, expressada por aqueles que aqui se tornaram escravizados, que por sua vez se interligou à religião "oficial" do país, o catolicismo, sendo essa uma estratégia de sobrevivência e reinvenção. Em termos metodológicos a pesquisa se assentou sob os pressupostos qualitativos, com um desenho narrativo. Empregou três recursos para erigir os dados: observação participante; elaboração de um diário de campo e entrevistas semiestruturadas. Quanto ao lócus investigativo, tratou-se do município de Lambari/MG. Participaram do estudo oito depoentes, tendo sido eleitos em razão da influência e representação que desfrutam no espaço congadeiro da localidade, assim como em razão da atípica variedade de gênero que se encontrou na capitania deste universo festivo cultural. No que concerne aos resultados, verificou-se a existência do ensino, se bem que com certa mudança na acepção, aproximando-se mais de uma perspectiva interacionista, do que da tradicional transmissibilidade oral, essencialmente empirista. De igual modo, constatou-se que houve modificações no modo de ensinar e aprender os saberes congadeiros, aos novos aprendizes, que, apesar de alguns aspectos intuitivos no modo de aprender, tem suscitado

\footnotetext{
${ }^{1}$ Mestra em Educação. Docente na Rede Estadual de Ensino de Minas Gerais em Lambari/MG. Lambari/MG Brasil. Endereço eletrônico: aline.gu@gmail.com

${ }^{2}$ Doutor em Educação. Docente na Universidade Federal de Lavras (UFLA), vinculado ao Departamento de Educação Física e ao Programa de Pós Graduação em Educação. Lavras/MG - Brasil. Endereço eletrônico: fabioreis@ufla.br

${ }^{3}$ Doutora em História. Docente na Universidade Federal de Alfenas (UNIFAL-MG), vinculada ao Departamento de História e ao Programa de Pós Graduação em Ensino de História (ProfHistória) na Universidade Federal Fluminense. Niterói/RJ. Brasil. Endereço eletrônico: 1nascimentomonteiro@gmail.com

4 Doutor em Educação Escolar. Docente na Universidade Federal de Lavras (UFLA), vinculado ao Departamento de Educação Física e ao Programa de Pós Graduação em Educação. Lavras/MG - Brasil. Endereço eletrônico: kleber2910@gmail.com
} 
preocupação o desinteresse em relação aos saberes (tradicionais) atinentes à congada, sob pena da descontinuidade da propagação desse patrimônio cultural (imaterial) da humanidade.

Palavras-chave: Congada; Experiência Formativa; Ensino; Aprendizagem; Ancestralidade.

\begin{abstract}
This an article whose content portrays a scientific research on the formation aspects (relationship between teaching and learning) contained in Congada. At the epistemological level, we situate it as a historical phenomenon, originally of African origin (Banta, marked by the appreciation of ancestry and the sacred), which suffered resignifications when intermingling with Brazilian culture, for those who became slaves here, which in turn started to connect with the country's "official" religion, catholicism, this being a strategy of survival and reinvention. In methodological terms, the research was based on qualitative assumptions, with a narrative design. It used three resources to raise the data: participant observation; elaboration of a field diary and semi-structured interviews. As for the investigative locus, it was the municipality of Lambari/MG. Eight interviewees participated in the study, having been elected due to the influence and representation they enjoy in the locality's universe, as well as due to the atypical variety of genre found in the captaincy of this cultural festive universe. With regard to the results, the existence of teaching was verified, albeit with a certain change in the meaning, approaching it more from an interactionist perspective, than from the traditional oral transmissibility, essentially empirical. Likewise, it was found that there were changes in the way of teaching and learning congadeiro knowledge, applied to new apprentices, who, despite some intuitive aspects in the way of learning, it has raised concern the lack of interest in relation to knowledge (traditional) pertaining to Congada, under penalty of the discontinuity of the propagation of this (immaterial) cultural heritage of humanity.
\end{abstract}

Keywords: Congada; Experience Formative; Teaching; Learning; Ancestrality.

\title{
Introdução
}

A congada exprime uma das manifestações (plural) da cultura (híbrida) brasileira. Trata-se de uma expressão popular que conjuga: dança, festa (de conotação sagrada ${ }^{5}$ ) e devoção, em diferentes regiões do país, notadamente, no Sudeste e Centro-Oeste do extenso território nacional. Diz respeito a um fenômeno multímodo, cuja abrangência e os matizes

\footnotetext{
5 Por se tratar de um conceito polissêmico, faz-se imprescindível delimitá-lo, sendo assim, adotaremos o entendimento de sagrado consoante à acepção postulada por Otto (1992). Sob essa abordagem, o sagrado reserva aspectos ditos racionais, ou seja, passíveis de uma apreensão conceitual através de seus predicados, e aspectos não racionais, que escapam à primeira apreensão, sendo exclusivamente captados enquanto sentimento religioso.
} 


\section{OO DEVIR EDUCAÇÃO}

ISSN: 2526-849X

culturais, conferem certa dificuldade em sua delimitação, por efeito em conceituá-lo (SOUZA, 2002).

Por intermédio de cortejos reais dos reis e rainhas congos, as festas de Congadas tomam as ruas das cidades com a devoção aos diferentes santos católicos e agrega os elementos do catolicismo com as práticas e códigos de traços religiosos de matriz afrobrasileira, especialmente a Umbanda. Muitos grupos se organizam em torno das irmandades negras de Nossa Senhora do Rosário, Santa Efigênia e São Benedito desde o século XIX (KISHIMOTO, TRONCARELLI, DIAS, 2015).

Os ternos, guardas, cortes, bandas ou batalhões são os nomes dados aos grupos que participam da festa - que ocorrem, sobretudo, entre os meses de maio a outubro, de acordo com a localidade. Segundo o folclorista Saul Martins, existem sete estilos de guarda: congo (ou congada, como em Lambari), moçambique, catopé, marujo, caboclinho, cavaleiro de São Jorge e vilão (MONTEIRO, 2016). Esses ternos são formados pelos dançantes, que liderados pelos capitães saem em cortejo pelas cidades, dançando e cantando para louvar seus santos e escoltar os reis e rainhas congos. Existem as festividades do Reinado - estrutura mais ampla e complexa, que abrange as guardas, os ternos e contempla vários rituais de devoção e festa - e a Congada, que além de se referir à festa, também dá nome às guardas do Congo.

Sob tal acepção, pode-se afiançar a Congada como patrimônio cultural imaterial da humanidade, visto que tal noção compreende uma complexidade de práticas, significados e sentidos, inscrita sob diferentes manifestações, quais sejam: cultural, artística, arqueológica, científica e tecnológica, etnográfica, integral, museológica, dentre outras. Em sentido amplo, patrimônio cultural se refere a tudo que criamos, valorizamos e queremos preservar: são os monumentos, obras de arte, festas, músicas e danças, os folguedos e as comidas, assim como, os saberes, fazeres e falares. Em última análise, trata-se daquilo que produzimos com as mãos, as ideias e a fantasia (FONSECA, 2004).

Em razão dessa amplitude de expressões culturais, a Congada tem suscitado interesses investigativos em diferentes áreas das ciências humanas e sociais. Alguns assentados no campo da historiografia sob a prospecção da Congada, a exemplo de (SOUZA, 2002; SILVA, 2003; NASCIMENTO, 2009). Outros ao abrigo da antropologia/social (BRANDÃO, 1985; CARMO, MEDONÇA, 2008; COSTA, 2006), há ainda alguns ligados ao campo da psicologia social (LIMA-FERREIRA, MAHFOUD, SILVA, 2011; JESUS JUNIOR, 2003). 
Contudo, nota-se que no âmbito da Educação, são escassas as pesquisas que se inclinaram a cotejar às experiências ${ }^{6}$ formativas $^{7}$ que compreendem a Congada. Em que pese mais recentemente, a investigação de Costa (2020) tenha fornecido alguns indícios a esse respeito, ao estabelecer outras categorias de análise pelas quais o estudo se enveredou, houve certa dispersão no que diz respeito a essa correlação entre experiências formativas e a congada, com isso, as discussões se "dissolveram" no interior do estudo.

Pois bem, em razão dessa conjuntura até aqui exposta, empreendeu-se uma investigação científica na qual cotejamos as implicações que a Congada engendra na constituição de experiências formativas (relação entre ensino e aprendizado) para os participantes que interagem e se apropriam de seus saberes. Convém, no entanto, esclarecer que a acepção de formação sobre a qual o estudo se fundamenta, baseia-se no conceito de pedagogias culturais, postulado por Andrade e Costa (2015) a partir da década de 1990. Em decorrência disso, ampliaram-se as concepções sobre os espaços de aprendizagem e a percepção do papel da cultura no processo de construção e aquisição do conhecimento historicamente construído.

Esta iniciativa científica se justifica em razão da ausência de pesquisas que analisem as implicações formativas provenientes da Congada, de igual modo, endosse o alargamento de compreensão dos processos educacionais para afora dos espaços de escolarização formal. Em especial, estudos que tragam à baila os saberes subalternos ${ }^{8}$ que:

[...] discutem e apresentam os mecanismos de produção de conhecimentos que instituiriam categorias analíticas e descritivas supostamente neutras para se falar desses "outros". Assim como apresentam o potencial transgressivo e, ao mesmo tempo, produtivo, de saberes outros, construídos não pelas certezas, como é comum na ciência ocidental, mas pela suspensão destas e pelo necessário questionamento epistemológico que sustentou os saberes hegemônicos (PELÚCIO, 2012a, p. 303).

\footnotetext{
${ }^{6} \mathrm{O}$ emprego do termo experiência para fins de texto se encontra ao abrigo da perspectiva de Bondia (2002, p. 21), definido como "o que nos passa, o que nos acontece, o que nos toca".

${ }^{7}$ Tendo vista que a palavras formação recebe distintas interpretações, no interior desta pesquisa sua acepção alinhar-se-á com o entendimento de Chauí (2003, p. 12), o que equivale a "introduzir alguém ao passado de sua cultura" e complementa a autora "é despertar alguém para as questões que esse passado engendra para o presente, e é estimular a passagem do instituído ao instituinte".

${ }^{8} \mathrm{O}$ emprego do termo "subalterno" não apresenta uma conotação depreciativa, conforme vislumbra, via de regra, o lugar comum, mas no contexto em questão, figura na qualidade de potência e capacidade de reinvenção de saberes, advindos de experiências humanas inusitadas.
} 
Convém ressaltar ainda que, basear-se na perspectiva dos saberes subalternos não implica apenas em saber escutar àqueles povos sistematicamente silenciados, mas propor outra "gramática, outra epistemologia, outras referências diferentes daquelas que aprendemos a ver como as "verdadeiras" ou as únicas dignas de serem aprendidas e respeitadas" (PELÚCIO, 2012b, p. 399). Portanto, essa pesquisa não se inscreve no campo que procura as evidências das narrativas ou se debruça em desvelar ou analisar as práticas corporais contidas nessa manifestação. Ou ainda em produzir evidências históricas relativas à Congada na comuna de Lambari-MG, apesar de revelar fatos intrigantes sobre essas questões que, em si, já avalizariam o estudo. Contudo, essa investigação concentra-se em aferir modos de ensinar e aprender os saberes característicos da congada, em razão de incidirem sobre a maneira de ser, estar, ler e se apropriar da organização social por parte daqueles que compõem o tecido (histórico) congadeiro.

Feita então essa contextualização mais panorâmica da pesquisa, por assim dizer, doravante detalharemos a estrutura metodológica sobre a qual a pesquisa se assentou.

\section{Pressupostos metodológicos do estudo}

Tratou-se de uma pesquisa arquitetada sob os pressupostos qualitativos. Ao anotar os aditamentos desse tipo de abordagem, Sampieri; Collado; Lucio (2013, p.102) elucidam que essas investigações pretendem cotejar informações de forma independente ou conjunta sobre “os conceitos ou as variáveis a que se referem. Logo, podem integrar as medições ou informação de cada uma das variáveis ou conceitos para dizer como é e como se manifesta o fenômeno de interesse".

Pode-se, então, afirmar que, ao eleger a dimensão qualitativa, o pesquisador volta-se para a busca do significado de um fenômeno, porque este tem um papel organizador na vida dos seres humanos. Aquilo que as "coisas" (manifestações, ocorrências, fatos, eventos, vivências, ideias, experiências, sentimentos, assuntos) representam dá "molde" ao cotidiano das pessoas. Em um outro nível, os significados que as "coisas" ganham passam também a ser partilhados culturalmente e, assim, organizam o grupo social em torno dessas representações e simbolismos. Talvez isso justifique a abrangência e o alcance dessa modalidade tão expressiva de pesquisa, bem como, o interesse de muitos pesquisadores em adotá-la 
(BODGAN e BIKLEN, 1994; LeCOMPTE, MILLROY e PREISSLE, 1992; DENZIN e LINCOLN, 2000; VIDICH e LYMAN, 2000).

Mesmo porque, não seria factível identificar e compreender as experiências formativas dos congadeiros por intermédio de uma acepção quantitativa, visto que tais dimensões subjetivas (próprias do sujeito epistêmico) e inter-relacionais não são quantificáveis em critérios e medições. Ademais, "os métodos quantitativos supõem uma população de objetos de observação comparáveis entre si e os métodos qualitativos enfatizam as especificidades de um fenômeno em termos de suas origens e sua razão de ser" (HAGUETTE, 1994, p. 392). Parece-nos honesto caminhar nessa direção que, a despeito de dispor de um delineamento prévio para erigir a investigação, não se trata de uma escolha definitiva, tampouco linear, na medida em que há constantemente necessidades de "calibrar" o processo heurístico para que se possa atingir o objeto (epistemológico) eleito e perscrutado.

Em termos de enfoque, optou-se por um desenho narrativo. Trata-se de uma perspectiva "que fornece estrutura para entender o indivíduo ou grupo e escrever a narrativa contextualizando a época e o lugar onde a pessoa ou o grupo viveu ou, ainda, onde as experiências e os eventos ocorreram - (SAMPIERI; COLLADO; LUCIO, 2013, p. 509)".

Três foram os recursos utilizados para erigir os dados, a saber: observação participante; elaboração de um diário de campo e entrevistas semiestruturadas (LUDKE, ANDRÉ, 1986). Destaca-se que a observação participante fora primordial para a interação com àquele contexto cultural, na intenção de captar os silêncios e compreender as entrelinhas dos enunciados produzidos pelos congadeiros, seja por ocasião das entrevistas, ou até mesmo ao longo de conversas e interações informais (ANDRÉ, 2013). Aliado a isso, o uso do diário de campo figurou como um recurso imprescindível, dado que possibilitou registrar: impressões, surpresas, indagações e estranhamentos. Sem ele, muito provavelmente a pesquisa não se concluiria, ou quiçá enfraquecer-se-ia no que concerne à produção do material empírico (LUDKE, ANDRÉ, 1986).

Em relação às entrevistas, optou-se pelo modelo semiestruturado, justamente porque confere a liberdade de se inserir questões, para além daquelas que constam no roteiro inicial, a fim de que se amplie os conceitos ao permitir o acesso as experiências vividas pelos entrevistados (SAMPIERI; COLLADO; LUCIO, 2013).

Para escolha dos participantes, inicialmente foi estabelecido um contato com as lideranças da congada na cidade de Lambari/MG - mais à frente detalharemos o lócus da 
investigação e a razão pela qual ele fora selecionado para o estudo - sendo que posteriormente a rede de sociabilidade (depoentes) foi se ampliando. Além disso, outra decisão adotada para seleção dos pesquisados observou à diversidade de gênero presente nas capitanias dos ternos ${ }^{9}$. Em face disso, oito ${ }^{10}$ participantes integraram o quadro de depoentes, sendo cinco homens (Jorge Luiz Julio, o Binho, Antônio Luiz de Oliveira, o Madô, Anderson do Carmo e Benedito) e três mulheres (Ângela Rodrigues Marciano de Castro, Elaine Rodrigues de Castro, Maria das Mercês e Rosário).

A investigação foi desenvolvida entre os anos de 2018 e 2019, tendo aproximadamente treze (13) meses de duração, desde seu planejamento inicial até a consecução.

\section{Quanto ao Lócus da pesquisa}

A pesquisa foi desenvolvida na cidade de Lambari, localizada no sul de Minas Gerais, na região que engloba os municípios que constituem o Circuito das Águas Minerais (próximo a São Lourenço, Cambuquira e Três Corações). Foi distrito de Campanha até 1901, quando se emancipou sob a alcunha de Águas Virtuosas de Lambary, sendo que em apenas 1930 tornouse reconhecido como município de Lambary. Tem hoje uma população de quase 20 mil habitantes e sua principal atividade econômica é a agricultura, em especial, a cafeeira ${ }^{11}$ (SILVA, 2011).

A festa da Congada na referida cidade tem duração de três dias, ocorrendo, em tese, próximo a 13 de maio. A data remete à Abolição da Escravidão, ocorrida em 1888. Há dois rituais que antecedem a festa: a Exaltação à Santa Cruz que ocorre no dia 3 de maio e a

\footnotetext{
${ }^{9}$ Nome dado aos grupos de Congada. Variam em número de participantes, nas roupas e nos instrumentos utilizados, mas tem em comum, de um modo geral, a organização de seus componentes.

${ }^{10}$ Os participantes manifestaram aquiescência em relação ao estudo, ao assinarem o termo de consentimento livre e esclarecido. O projeto de pesquisa fora submetido e aprovado pelo Comitê de Ética em Pesquisa com Seres Humanos de uma IES, situada na região sul do estado de Minas Gerais (CAAE: 22479219.0.0000.5148). Informamos, contudo, que ao explicarmos aos participantes que seria preservada sua identidade, ou seja, suprimido o nome, alguns não concordaram com essa política ética, condicionando a participação com a exposição do nome, ou de sua antonomásia. Trata-se de uma situação, inclusive, prevista na Resolução $\mathrm{N}^{\circ} 510$, de 07 de abril de 2016, artigo XVI. Sendo assim, alguns dos nomes foram conservados, enquanto que outros são fictícios, ou codinome. Neste trecho, optamos por colocar o nome completo daqueles que pleitearam que suas identidades fossem reveladas e apenas o nome fictício daqueles que optaram pelo anonimato.

${ }^{11}$ Segundo dados do IBGE: Disponível em: https://cidades.ibge.gov.br/brasil/mg/lambari/panorama. Acesso em: 9 de janeiro 2020.
} 
Subida do Mastro no dia 10 de maio. Em Lambari, 4 mastros são levantados com suas bandeiras em louvor a São Benedito, Santa Efigênia e Nossa Senhora do Rosário. Na madrugada de 12 para 13 de maio um "terno" vai até o Cruzeiro do município para a Alvorada, simbolizando o anúncio da libertação dos escravizados (COSTA, 2020).

Ainda consoante a autora, a festa é oficialmente (mas não exclusivamente, conforme veremos adiante) "católica" e integra o calendário oficial de Lambari. A comunidade católica que congrega os ternos é a de São Benedito, porém, os grupos não reverenciam apenas este representante sagrado, há também devoção: a Santa Efigênia; Nossa Senhora do Rosário; Nossa Senhora de Aparecida e Santo Antônio de Categeró.

Em Lambari existem hoje oito ternos de congada cujos nomes são: Estrela Cadente, Rainha das Águas, Flor de Maio, Treze de maio, São Benedito, Astro Rei, Nossa Senhora do Rosário e Garça Branca. Três deles são comandados por mulheres: o Estrela Brilhante, o Astro Rei e o Flor de Maio. Trata-se de um fato inusitado dado a tradição (patriarcal) da Congada, encontrar-se ternos sob a regência de mulheres, eis, portanto, um dos aspectos que nos influenciou a escolha da localidade da pesquisa.

Aliás, o último terno supracitado (lê-se, o Flor de Maio), sob condução feminina, fazse notório,

[...] como o terno das mulheres, visto que está sob o comando de Carmelina, a capitã de guia também é mulher e na frente do terno só há mulheres. Aos homens só é permitido participar tocando os tambores ao fundo. Há um terno de Moçambique que tradicionalmente percorre as ruas da cidade junto com a Congada - é a Companhia Folclórica Moçambique Santo Antônio de Categeró. A quantidade de pessoas que participam da Congada é variável visto que a cada ano entram e saem participantes. Os ternos têm de 10 a 80 pessoas e todos estão localizados nos bairros mais simples da cidade, a dizer, Vila Brasil, Vila Nova e Campinho (COSTA, 2020, p. 30).

Um aspecto histórico identificado por esse estudo - em que pese, reitera-se, não se tratar do fito desta investigação -, refere-se à constatação de haver poucos registros de fontes (lê-se documentos escritos) a respeito da presença dos ternos, sequer dos mais antigos, haja vista que alguns estão em atividade desde meados da década de $1980^{12}$. Convém destacar que os registros das associações dos grupos ocorreram apenas mais recentemente, sendo eles próprios incumbidos de salvaguardar seus legados históricos. Somente em 2012 inaugura-se a

\footnotetext{
${ }^{12}$ Apesar não ter sido o foco investigativo da referida pesquisa a busca por fontes históricas escritas, a autora encontrou uma reportagem da revista National Geographic de 1979 sobre a congada de Lambari.
} 
Associação do Folclore e Manifestações artísticas e Culturais de Lambari (AFOMAC), que passa a representar e organizar sistematicamente às manifestações folclóricas da cidade.

Na tentativa de compilar a descrição dos ternos, Costa (2020) congregou-os em um quadro, cuja estrutura contém: o nome, ano de constituição, os ternos e capitães correspondentes, conforme se observa a seguir.

Quadro 1 - Lista de Associações de Congadas de Lambari

\begin{tabular}{|c|c|c|c|}
\hline NOME DA ASSOCIAÇÃO & $\begin{array}{c}\text { ANO DE } \\
\text { CONSTITUIÇÃO } \\
\end{array}$ & $\begin{array}{l}\text { NOME DO } \\
\text { "TERNO" }\end{array}$ & $\begin{array}{c}\text { CAPITANIA } \\
\text { RESPONSÁVEL } \\
\end{array}$ \\
\hline $\begin{array}{c}\text { Associação das Congadas Grupo Folclórico } \\
\text { Terno Rainha das Águas }\end{array}$ & 1996 & $\begin{array}{l}\text { Terno Rainha das } \\
\text { Águas }\end{array}$ & $\begin{array}{l}\text { Capitão Jorge Luiz } \\
\text { (Binho) }\end{array}$ \\
\hline $\begin{array}{l}\text { Associação das Congadas Grupo Folclórico N. S. } \\
\text { do Rosário e São Benedito }\end{array}$ & 1999 & $\begin{array}{l}\text { Terno Estrela } \\
\text { Cadente }\end{array}$ & Capitã Ângela \\
\hline $\begin{array}{l}\text { Associação de Congada Grupo Folclórico de } \\
\text { Mulheres Santa Efigênia Flor de Maio }\end{array}$ & 2001 & Terno Flor de Maio & Capitã Carmelina \\
\hline $\begin{array}{c}\text { Associação de Congada Grupo Folclórico Treze } \\
\text { de Maio }\end{array}$ & 2006 & $\begin{array}{l}\text { Terno Treze de } \\
\text { Maio }\end{array}$ & Capitão Ditão \\
\hline $\begin{array}{l}\text { Associação da Congada Grupo Folclórico N. S. } \\
\text { do Rosário e São Benedito }\end{array}$ & 2009 & Terno São Benedito & Capitão Marcio \\
\hline $\begin{array}{c}\text { Associação das Congadas Grupo Folclórico } \\
\text { Princesa Isabel }\end{array}$ & 2012 & $\begin{array}{l}\text { Terno Princesa } \\
\text { Isabel (fora de } \\
\text { atividade há } 3 \text { anos) }\end{array}$ & Capitão Wilson \\
\hline $\begin{array}{l}\text { Associação do Folclore e Manifestações } \\
\text { artísticas e Culturais de Lambari }\end{array}$ & 2012 & ---- & Mariângela Catão \\
\hline $\begin{array}{c}\text { Associação das Congadas Grupo Folclórico N. S } \\
\text { do Rosário e Pequenos Colibris }\end{array}$ & 2014 & $\begin{array}{l}\text { Terno N. S. do } \\
\text { Rosário }\end{array}$ & Capitão Rodolfo \\
\hline $\begin{array}{l}\text { Associação das Congadas Grupo Folclórico São } \\
\text { Vicente de Paula e Nossa Senhora do Rosário }\end{array}$ & 2014 & Terno Astro Rei & Capitã Dora \\
\hline Irmandade Santa Cruz & 2018 & Terno Garça Branca & Capitão Jorginho \\
\hline
\end{tabular}

Fonte: Costa (2020)

Ora, após expor a especificidade dos ternos no que diz respeito ao levantamento quantitativo (número bastante significativo), as lideranças, as respectivas datas de fundação via registro da AFOMAC e explicitar a composição metodológica sobre a qual a pesquisa se configurou, discorreremos na próxima seção uma breve tessitura histórica da congada. Embora não seja o desígnio primário da pesquisa, segundo já dissemos antes, trata-se de situála historicamente para que possamos identificar a produção de saberes conectados à ancestralidade. 


\section{A constituição histórica da Congada: da ancestralidade à ressignificação no Brasil}

A literatura especializada certifica que a origem da congada se remete à cultura $\mathrm{e}$ cosmologia banta (MARTINS, 1997; MELLO e SOUZA, 2002; DAMASCENA, 2012; HEYWOOD, 2012; DELFINO, 2015; SILVA, 2016; SOUZA, 2018). A esse respeito, Silva (2016) analisou como os autores do início do século XX utilizaram o termo "banto" compreendendo diferentes grupos étnico-linguísticos e, por isso, acabaram por classificá-los racial e/ou culturalmente. Apesar dos riscos que se incorre ao estabelecer generalizações, para esse autor o estado de Minas Gerais recebeu grande número pessoas negras escravizadas, oriundas de diversas regiões africanas de etnia banto ${ }^{13}$.

No modo de vida dos povos bantos, a ancestralidade é um valor imprescindível para sua cosmologia, pois não há divisão rígida entre os mundos dos vivos e dos mortos, entre presente e passado. Conservar a comunicação com os ancestrais, seja por meio dos rituais religiosos, ou pela recriação do legado deixado pelos antepassados, é vital. Sobre isso, Martins (1997, p. 37) enfatiza que os bantos concebem "o indivíduo como a expressão de um cruzamento triádico [a saber]: os ancestrais fundadores, as divindades e 'outras existências sensíveis', o grupo social e a série cultural".

Com efeito, convivem de maneira harmônica e enredada: o secular e o sagrado; o corpo e a palavra; o som e o gesto; a história individual e a memória coletiva ancestral; o divino e o humano; a arte e o cotidiano. Em razão dessa perspectiva fenomenológica de existência, por assim dizer, os bantos "mantém ligados o presente e o passado, o descendente e seus antepassados num gesto sagrado que funda a própria existência da comunidade" (MARTINS, 1997, p. 36).

Essa força vital vem à lume quando os congadeiros acionam as suas tradições ancestrais para recriar anualmente as festividades. Residiria, portanto, na ancestralidade, o baluarte que esteia a prática da cultura congadeira, sendo ela reorganizada (religiosamente falando) quando adentra "o tecido cultural e simbólico brasileiro (MARTINS, 1997, p. 35)".

\footnotetext{
${ }^{13}$ Acompanhamos aqui a definição de Yeda Pessoa de Castro, citada por Leda Martins na qual “o domínio banto compreende diversas línguas faladas em toda a África subequatorial, em territórios que vão da linha do equador até a África do Sul, entre os do Gabão, Zaire, Camarões, Angola Uganda, Quênia, Zâmbia, Zimbabwe, Moçambique [...] O termo banto, plural de 'muntu', homem, significa povo [...] O quicongo, falado pelos bacongo, o quimbundo, falado pelos ambundos e o umbundo, pelos ovimbundo, são línguas que fazer parte do território banto" (CASTRO apud MARTINS, 1997, p. 28).
} 
Notemos que a reedição dos cortejos de reis e rainhas africanos pelos negros aqui escravizados, modificou-se à medida que novos significados se atrelaram aos originários. Com isso houve o reatamento de laços identitários e sociais de uma população "sequestrada" de sua terra, consequentemente, lançada ao trabalho compulsório. A esse respeito Costa (2020) explana que, se a diáspora africana foi uma vivência na qual a morte estava presente, as manifestações culturais criadas por essa comunidade negra encarcerada devem ser consideradas experiências de reinvenção. Ora, se a travessia do Atlântico tirou muitas vidas e dilacerou laços de sociabilidade forjados em África, as culturas criadas no Brasil proporcionaram para muitas e muitos a chance de reinventar sua existência, sintetizada no aforismo: a desenvoltura de fazer festa na fresta.

Nessa esteira de reflexão, pode-se considerar que as irmandades católicas constituídas também por e para pessoas negras, em grande medida, encharcaram-se de expectativa para que novos laços sociais fossem produzidos e redes de solidariedade se fortalecessem. Trata-se de uma constatação verificada por Costa (2020), ao anotar que essa admissão de negros escravizados e libertos sendo integrados, inclusive aos rituais (sagrados) católicos - desde batismos, casamentos até cortejos fúnebres -, denotava uma conquista (em âmbito cultural/social) expressiva pelo fato de que outrora havia um interdito por parte das irmandades "brancas". A autora em questão ressalta ainda que tal integração entre as irmandades conferia, ao mesmo tempo, a esperança de auxílio aos doentes e pessoas com idade avançada em situação de vulnerabilidade social. Além disso, representavam a possibilidade para muitos escravizados de amealhar suas economias com o objetivo de comprar a própria liberdade. Quanto a isso anota Delfino (2015):

As irmandades constituíam-se em associações religiosas cujos leigos se reuniam em torno de uma devoção ou orago. Suas regras de funcionamento e gestão estavam regulamentadas em um estatuto de Compromisso. Por este regimento se estabeleciam os critérios de admissão, os valores a serem pagos pela entrada, anuidades, esmolas aos santos, [...] Eram suas principais finalidades promover o culto público devocional e assistência material e espiritual aos irmãos vivos e defuntos (p. 18).

Sendo assim, no início do século XIX, com o propósito de pagar promessas por graças recebidas, pari passu para demonstrar sua fé e até mesmo alvitrar a conquista de novos associados, os componentes das irmandades formavam cortejos e saíam às ruas com flâmulas de reverência sacra (DELFINO, 2015). Sempre acompanhados de músicas e danças 
embaladas pela vibração dos sagrados tambores africanos, esses rituais culturais (ancestrais) negros, com o tempo, tornaram-se tradição. Ao passo que até nos dias atuais, há ainda um grande número de irmandades negras em Minas Gerais, que prestam sua religiosidade a Nossa Senhora do Rosário, São Benedito, Santa Efigênia e Nossa Senhora das Mercês. Na realidade, esse é um esforço para conservar firmemente suas práticas sagradas, a despeito das obstinadas tentativas de silenciamento e descaracterização desse patrimônio imaterial cultural (COSTA, 2020).

De acordo com Robert Slens (1988), “a escravidão em Minas, no fundo, fazia parte do complexo econômico da plantation" (p. 234), pois a economia da província mantinha muitos vínculos com o setor de exportação - destino para a maioria dos escravos após 1850. Com o fim da mineração, ainda no século XVIII, os escravos que trabalhavam nessa atividade foram trabalhar nas atividades ligadas à agricultura. Na segunda metade do século XIX, o sistema escravista brasileiro continuava próspero e dinâmico. O setor cafeeiro, localizado na região centro-sul do país, como em Minas Gerais, São Paulo e Rio de Janeiro, mantinha sua intensa dependência com a mão de obra escrava e os números dos censos realizados no século XIX indicam uma sociedade mineira em pleno crescimento. Em 1872, o censo apontou Minas Gerais como a província com maior número de escravos do país. Em 1885, a população cativa da província somava 276.275 indivíduos, diminuindo para 191.952 em 1887 (COTA, 2013).

Especialmente para o sul mineiro, pesquisas recentes apontam para o dinamismo socioeconômico da região durante o século XIX, com a circulação de produtos voltados para o mercado interno, a participação política no Império e a alta concentração de escravizados. Ademais, como assinala Custódio Sobrinho (2018), houve em várias cidades da região, muitos embates e conflitos que levaram à formação dos movimentos abolicionistas entre 1880 e 1888 (CUSTÓDIO SOBRINHO, 2018) e que estavam associados a diversos festejos congadeiros pelas diferentes cidades da região.

Pois bem, após esta breve descrição do encadeamento histórico entre ancestralidade e a ressignificação da congada na chegada ao Brasil, a próxima seção dedicar-se-á a arrazoar sobre o fito central do estudo: a formação (relação ensino/aprendizagem) derivada do espaço congadeiro.

\section{Sobre a concepção de ensino presente na congada}


“(...) porque a vida é assim ó, cê nasce aprendendo e morre sem saber de nada"

(Depoente Benedito)

A narrativa que se traz à baila - uma espécie de moldura de abertura da seção - de autoria de um dos depoentes, traduz em grande medida a concepção epistemológica na qual a investigação se baseou. No teor da fala do entrevistado, há uma acepção de aprendizagem que compreende o "sujeito epistêmico como constituído num processo radicalmente histórico, tendo como ponto de partida a organização biológica dada na bagagem hereditária [o nascimento]" (BECKER, 1993, p. 17). Contudo, se torna sujeito [diuturnamente] na proporção em que compõem e constrói o tecido histórico. Nas palavras do aludido autor "é sujeito histórico na medida em que traduz sua organização biológica pelas ações próprias da cultura na qual vive" (idem).

Sob essa acepção (interacionista de conhecimento, vale destacar), interessava-nos saber se há ensino na e sobre a Congada? Do mesmo modo, o que pode ser aprendido na e por intermédio da Congada? Não obstante, quem ensina, com efeito, de que maneira o faz? São indagações de ordem epistemológica - em certa medida didática - que se procurou perscrutar, ora se valendo das entrevistas, ou mediante as observações participantes que foram realizadas em diferentes momentos do trabalho investigativo.

Antes, porém, de respondê-las, é preciso compreender que as relações formativas de ensino e aprendizagem não se circunscrevem ao espaço escolar - embora reconheçamos que essa instituição seja por excelência esse espaço potencial, logo deva ser valorizada -, pois se assim o fosse, o entendimento de aprendizado assentar-se-ia na ótica empirista e não interacionista segundo destacamos. Isto equivale a dizer que a aprendizagem do sujeito ocorreria estritamente exterior a ele, ou seja, "externamente ao sujeito sem que a atividade endógena dele seja, por um momento sequer, colocada em questão" (BECKER, 1993, p. 57).

Para responder as inquirições realizadas anteriormente, pautamo-nos na perspectiva teórica dos Estudos Culturais, sob a compreensão de que os processos educativos não se restringem ao interior da escola. Eles podem acontecer em espaços sociais distintos, inclusive no contexto da Congada de Lambari-MG, mesmo porque a aprendizagem decorre da relação dialética entre sujeito (histórico) e objeto (universo cultural/social/imaginativo). Em última análise, a novidade trazida pela aprendizagem e sua continuidade é garantida pelo 
desenvolvimento do aprendiz, ao interagir com o mundo que habita e que (potencialmente) transforma (BECKER, 1993).

Pois bem, perguntamos então aos entrevistados como a congada era ensinada aos demais praticantes de Lambari e quais eram os momentos dedicados a isso. Para nossa surpresa todos os entrevistados foram enfáticos ao afirmar a inexistência de um espaço-tempo definido para que o ensino e a aprendizagem acontecessem. Trata-se de uma constatação intrigante, ao se considerar a existência de um legado tradicional nas comunidades negras em se tratando da transmissibilidade de saberes, rituais e convenções. Tal qual observou Martins (1997), quando certificou que há uma característica muito comum entre as sociedades africanas, em geral, e em especial nos povos bantos: a tradição oral. Essa abordagem de ensino se caracteriza pelo fato do saber ser transmitido informalmente pelos mais velhos do grupo às novas gerações por via da oralidade.

Ao que tudo indica, houve certa ressignificação em relação à construção e apropriação dos saberes historicamente situados no interior do universo pesquisado, tal qual a maneira de apresentá-los, já que alguns afirmaram que aprenderam fazendo, enquanto que outros observando. A julgar pela similaridade do teor das respostas, não exporemos todas elas, contudo apresentaremos algumas que traduzem uma espécie de "concepção geral sobre o ensino" doravante.

[...] eles não ensinava, a gente é que ficava prestando atenção neles (Binho).

[...] o Fernando veio ensinar a fazer e eu fiquei ajudando ele e aprendi, se for para fazer eu faço, fiquei lá ajudando ele, mais faço [...] isso vai acontecendo (Madô).

[...] com quinze anos de idade eu já comecei a pegar isso, só que ninguém me ensinou. Ninguém me ensinou que tinha que rezar, também não o verso, eu sabia de uns versos mais antigos porque eu escutava os mais antigos cantar [...] mas muitas vezes não sabia o sentido daquele verso, então às vezes no começo a gente ficava meio perdido (Benedito).

Depreende-se das narrativas uma perspectiva de ensino que se distancia, em partes, da transmissibilidade (tradicional) de saberes, uma vez que os processos ocorreram de modo mais autônomo, sendo pelo aprender fazendo, ou lançando mão da própria observação. Embora se note também a presença do ensino transmitido quando a depoente (Madô) evoca a influência do Fernando no seu processo de aprendizagem, conquanto ela considera que o êxito decorreu do próprio exercício, isto é, da experiência. 


\section{Q0 DEVIR EDUCAÇÃO \\ ISSN: 2526-849X}

Parece-nos que tal mudança possa ter relação com a organização social contemporânea - trataremos disso na próxima seção, quando abordaremos a questão do diálogo geracional suscitado pela Congada - e o próprio modo com que a sociedade da informação lida com o conhecimento. Além disso, tem-se a questão do enredamento do ato de ensinar que, de fato, não se trata de uma tarefa simples.

Por isso persistem, de tal modo que afiançar "a ancestralidade como sabedoria pluriversal ressemantizada por essas populações em diáspora emerge como um dos principais elementos que substanciam a invenção e a defesa da vida" (RUFINO, 2019, p. 15). Manter a cultura congadeira é, portanto, a marca da reinvenção e da reconstrução da vida em meio à escassez, transgredindo um mundo desencantado. Transgressão é aqui entendida como "invenção de novos seres para além do cárcere racial, do desvio e das injustiças cognitivas" (idem, p. 11).

Há ainda uma importante justificativa para o fundamento do ensino (empirista) basearse na transmissibilidade dos saberes oralmente (ancestrais e culturais), que fora a figura (histórica) marcante dos griôs. Eles eram trovadores ou menestréis africanos que percorriam diversas regiões e atuavam como: músicos, embaixadores ou genealogistas (COSTA, 2020). Os músicos tocavam instrumentos, cantavam e preservavam a música antiga, ao passo que os embaixadores eram responsáveis pela mediação entre famílias em caso de desavenças. Já os genealogistas tinham conhecimento das linhas de ascendência das famílias e, ao mesmo tempo, atuavam como historiadores, poetas e grandes viajantes (COSTA, 2020). Em razão de transitarem por inúmeros territórios, os griôs também contavam estórias e carregavam grande parte do conhecimento histórico africano, ensinando-o pelas regiões onde percorriam (HAMPATÉ-BÂ, 2010).

Ao expor o papel desses trovadores e relacioná-los à questão da ancestralidade pudemos conhecer, ainda que em partes, se houve ensino e de que modo se deu o processo de aprendizagem dos depoentes acerca dos saberes relativos à Congada. Resta, no entanto, saber quanto às outras duas questões que listamos anteriormente, quais sejam: como os praticantes ensinam os novos aprendizes e o que ensinam sobre a Congada?

Pretende-se, então, na próxima seção expor os desafios que enleiam o ensino e a aprendizagem dos iniciantes, notadamente em relação aos conflitos geracionais nos quais isso se perfaz. De igual modo, pretende-se desvelar as estratégias que o grupo adota para preservar, antes de tudo, a cultura cuja Congada representa. 


\section{Outros tempos, novos desafios: os novos congadeiros e as questões geracionais}

No novo tempo, apesar dos perigos; Da força mais bruta, da noite que assusta, estamos na luta; Pra sobreviver, pra sobreviver, pra sobreviver; Pra que nossa esperança seja mais que a vingança; Seja sempre um caminho que se deixa de herança (Ivan Lins, 2004)

Com base nas observações participantes, bem como nos escritos do diário de campo, pode-se constatar inúmeros registros concernentes aos esforços dos congadeiros e congadeiras (em especial, àqueles/as com idade superior a 30 anos) para concretizassem o ensino aos jovens que se introduzem naquele universo. Contudo, reiteramos aqui o que foi exposto antes, ou seja, o ato de ensinar não é uma tarefa simples, tampouco desprovido de complexidade. Isso se evidencia ao notarmos as investidas por parte dos congadeiros na utilização de metodologias distintas (no decurso da seção algumas serão mencionadas), a fim de que o ensino seja concretizado com êxito.

Sendo assim, indagou-se aos entrevistados para compararem como aprenderam os aspectos da congada (retomando às experiências como iniciantes) e de que maneira isso se sucede nos dias atuais. Houve concordância entre os depoentes que as interações educativas se modificaram significativamente no que se refere ao modo sobre a qual se ensina os saberes (ancestrais) sagrados e as distintas atribuições presentes no interior dos ternos.

Nessa esteira de questionamentos, averiguamos as principais estratégias que os congadeiros notaram ter se transformado ao longo do tempo. Um dos destaques diz respeito à "firmeza" (ou diretividade como disseram alguns) com que os praticantes mais velhos tratavam os sujeitos jovens no momento do ensino e da aprendizagem dessa manifestação (e nós obedecíamos, acrescentaram ainda). Outrossim, também destacaram a falta de interesse por parte das crianças e dos jovens no que concerne à valorização do conhecimento disponibilizado. Vejamos alguns depoimentos.

[...] Porque hoje eles querem levar da maneira deles. Cada um por si [...]. Eles não buscam orientação [...]. Não, não buscam o conhecimento: e se eu sentar com uma turma, "ah! Isso, isso aí é lá daquela época, ah não vamos mexer com esse negócio ai agora não, ah não tem nada a ver isso não, isso já passou" [...] Seria tão bonito não é? (Ângela).

[...] Porque não é simplesmente você montar um grupo e colocar na rua, você tem que saber o que você está fazendo [...] os grupos estão se montando, mas sem embasamento. Alguns têm interesse de aprender e outros não, às vezes a gente tenta fazer roda de conversa com eles, mas 


\section{Q0 DEVIR EDUCAÇÃO \\ ISSN: 2526-849X}

não funciona, porque a gente percebe que eles não querem aprender, então isso realmente é uma preocupação, porque a gente tem que passar uma mensagem, porque o grupo da congada tem uma filosofia, então não se trata exclusivamente montar o grupo e aí sair batendo (Elaine).

[...] eu tenho vontade sim de passar adiante essas coisas (refere-se aos saberes congadeiros) sabe, só que [...] não depende de mim [...]. Depende [em grande parte] de quem quer aprender [...] de quem vai aceitar não [...], porque você não pode forçar [...] a pessoa para aprender tem que vir dela [...] (Benedito).

[...] é uma pena não é! Porque nós daqui um tempo não vamos estar mais aqui, então seria um modo de dar sequência também, de continuar. O queremos é isso, mas aqui em Lambari os jovens estão se interessando pouco, infelizmente (Maria das Mercês).

Extrai-se das narrativas algumas questões intrigantes. Uma delas se refere a um consenso em relação à falta de interesse sistemático pela grande parcela dos aprendizes, em que pese citarem o empenho de alguns poucos. Não sabemos ao certo a origem dessa ausência crônica de interesse, tampouco se há uma única razão para que isso se aflore com tanta força. Quem sabe fosse necessário outro estudo que aprofundasse essa questão, ouvindo os jovens neófitos em relação ao universo da congada, já que nossa investigação não se deteve a esse público. Entretanto, inquirimos os congadeiros pesquisados se desconfiavam das razões que pudesse engendrar o desinteresse.

Alguns atribuíram as dificuldades à falta de embasamento para ensinar - uma percepção didática pertinente e de certo modo perspicaz. Sinalizaram, além disso, ter havido mudanças que influenciaram o controle disciplinar dos envolvidos e o respeito à hierarquia e as autoridades, com inclusão do acesso a algumas atividades específicas pelo grupo. Ademais aludem quanto à questão dos aparatos tecnológicos e sua interferência no desejo dos jovens aprenderem os rituais da congada (em alguns casos, parando até mesmo de participar da festa), uma situação que preocupa os ternos de modo geral.

Trata-se de uma constatação legítima, já advertida por Prandi (apud CAPUTO, 2012a) ao apontar o papel das transformações sociais no acesso ao conhecimento e os motivos da indiferença dos jovens frente aos saberes mais artesanais e suas consequências ao ensino. $\mathrm{O}$ autor afirma que o conhecimento intermediado pela escrita, "cujo acesso se amplia com a aquisição de livros, com as consultas às bibliotecas, e agora com a navegação na internet, não tem limites e muito menos segredo. Tudo está ao alcance dos olhos e nem é preciso esperar" (PRANDI apud CAPUTO, 2012a, p. 268)”.

Esse aspecto referente ao descrédito dos saberes sobre os quais os congadeiros experientes tentam apresentar aos mais jovens, trata-se de um exemplo inconfundível de 
conflito geracional. Ou seja, um grupo de praticantes foram ensinados de uma tal maneira, a partir da qual pretendem compartilhar com os neófitos, mas encontram dificuldades pelo fato deles se relacionarem com os saberes sob outra dinâmica e apropriação.

Sobre esse elemento geracional, Arendt (1992) afirma que o legado das pessoas mais velhas é imprescindível para que cada um seja capaz de se reconhecer como sujeito histórico. Para tanto, a autora ressalta que é necessário as gerações se capacitarem para nomear suas realizações, seus feitos, dar sentido a eles e, assim, poder ofertá-los àqueles que chegam ao mundo. É nisso que reside a potência do encontro intergeracional, o que acaba nos permitindo admitir que o espaço cultural congadeiro oportuniza essa influência mútua.

Conscientes dessa adversidade para o ensino dos principiantes, os praticantes mais velhos buscaram estratégias para enfrentar a situação. Um exemplo elucidativo diz respeito à flexibilização das regras de acesso aos instrumentos musicais, sendo que a convenção social tradicional exigia que apenas tocaria o tambor àquele dançante que estivesse um tempo significativo "no cordão" e já tivesse aprendido a tocar pandeiro, reco-reco e agogô. Em outros termos, o que fica explicito é que antigamente existia uma hierarquia rígida que impedia um novato de ter acesso aos tambores maiores. Observemos, pois, os depoimentos quanto a esse respeito.

[...] na questão dos instrumentos, não era assim, qualquer um que pegava, não mesmo! (Maria das Mercês).

[...] quando eu comecei a dançar, não tinha nem caixa, era um tamborim e era quadradinho. [...] depois passei a tocar reco-reco, porque antigamente, quando a gente tinha dez até quinze anos, não podia pegar a caixa grande, só depois de adulto, e hoje as crianças pegam normalmente, era muito rígido antigamente (Binho).

[...] eu tento passar, o que foi passou pra mim, mas está tendo um problema que ninguém quer ficar mais no cordão, quer caixa, quer caixa, as crianças, até eu falei uma vez para um rapaz que isso é errado, que antigamente a gente, todo terno tinha um limite, criança não podia pegar caixa (Binho).

As narrativas revelam outro modo interação com a hierarquia, os saberes e os artefatos que compreendem o universo da congada. Repare, no entanto, tratar-se de uma condescendência em relação ao acesso aos instrumentos que, de certa maneira, conserva a presença dos novos aprendentes. Fica evidente que essa reinvenção dos modos de ensinar se refere a uma expressão de luta para que a congada possa sobreviver, igualmente ao que sugere 
o excerto da canção de Ivan Lins (2004) que emoldura a abertura da seção. "E que esperança seja mais que a vingança e preserve-a como herança".

Os depoimentos desvendam também certo descompasso entre o desejo de ensinar (tradicional e empirista) e a expectativa de aprender dos mais novos, quiçá mais inclinada à perspectiva notadamente intuitiva. Ao mesmo tempo, coloca em cena a musicalidade e uma vontade unívoca: tocar o tambor, que nesse caso, independentemente de crenças, valores, pensamentos ou posicionamentos, figura na qualidade de resistência e de reinvenção pósdiaspórica.

Lembra-nos Martins (1997) que os tambores tinham significados sagrados, bem como as músicas e danças por eles embaladas. Os reis negros assim restituíam redes de significação desconhecidas pelos senhores escravistas, estabelecendo estratégica unidade entre os escravizados, independentemente de sua origem étnica. O tambor era um elemento significante que recuperava a lembrança, a memória e a história do sujeito africano, exilado de sua terra. Sendo assim, os rituais de coroação dos reis negros, sempre acompanhados dos tambores, "rompiam as cadeias simbólicas instituídas pelo sistema escravista secular e religioso, reterritorializando a cosmovisão e os sistemas simbólicos-rituais africanos[...]" (MARTINS, 1997, p. 39).

Em última análise, pode-se avalizar que aprender e ensinar a bater um tambor não se circunscreve à aquisição de habilidades manuais e rítmicas, pois ele (lê-se o tambor) se encontra imbuído de uma representação histórica da luta negra centrada na existência, na sobrevivência e na resistência, seja ela consciente ou não.

Pois bem, a próxima e última seção propõe-se responder a derradeira questão apresentada antes, na qual se interrogou sobre o que se aprende em termos religiosos na e por intermédio da congada? Mais especificamente, buscar-se-á examinar como os depoentes percebem os saberes ancestrais sagrados que figuram na condição de baluarte à congada, tendo em vista as ressignificações e o liame com o catolicismo em terras brasileiras.

\section{Consciência ancestral: disputas e preconceito em torno da ancestralidade}

No decurso da investigação, constatou-se que não há uma representação única em relação à raiz sagrada originária que compreende os elementos e as dimensões da Congada em Lambari/MG, segundo os praticantes que observamos e entrevistamos. 


\section{Q0 DEVIR EDUCAÇÃO \\ ISSN: 2526-849X}

Parece se tratar de uma espécie de "campo minado de significações", territórios, identidades e diferenças em constante disputa. Alegamos isso porque, apesar de termos percebido a importância da ancestralidade nos processos de ensino e aprendizagem no interior do grupo da congada, os modos como lidam com seus antepassados são bem distintos.

Identificamos dois depoentes, declaradamente umbandistas ${ }^{14}$, que destacaram o papel das experiências intermediadas pelo espiritismo no cotidiano do terreiro para a aquisição da maior parte dos seus conhecimentos sobre a congada. Enquanto que para os demais entrevistados essa questão não era tratada publicamente, uma evidência de que há uma intolerância religiosa velada. Ficou manifesto que falar em umbanda, ou mesmo em espiritismo, era um tabu, mas nem por isso a influência das religiões afrodescendentes deixou de existir naquele contexto.

Considerando essa "camuflagem" religiosa, interessava-nos saber como os praticantes da congada analisavam o convívio silencioso, mas bem conflitante, sobre os discursos e enunciados que circulavam entre os seus pares. Um entrevistado (Anderson) arriscou uma explicação mais geral, qual seja,

[...] cada entidade [isso incluí a própria dinâmica do terno] é duma forma, nenhuma é igual à outra, então cada uma tem uma forma diferente de aprender e fez lá no passado para trazer para o nosso presente.

Em seu trabalho sobre a educação das crianças nos terreiros de Candomblé, Stella Caputo (2012b) ressalta a importância dessa comunicação entre vivos e mortos, destacando o quanto tal diálogo é poderoso na manutenção da ligação entre os afrodescendentes e sua ancestralidade. Nessa direção, o mesmo entrevistado continua sua explanação,

A gente tem que fazer o particular nosso, para depois ser universal (Anderson).

Esclarece ele que, por um lado, existe um ritual desenvolvido da "porta pra dentro" que respeita as devidas particularidades dos sujeitos, por outro, àquelas práticas nas quais o grupo todo cooperativamente desenvolve na esfera pública, ou seja, o que foi nomeado de "universal". Isso denota que o depoente Anderson cultua a sua crença, a umbanda, porém em segredo, muito provavelmente para evitar preconceitos e segregação religiosa.

\footnotetext{
${ }^{14}$ São pessoas praticantes de Umbanda, uma religião brasileira constituída pelos povos negros, que atualmente sintetiza vários elementos das religiões africanas, ameríndias e cristãs.
} 


\section{OO DEVIR EDUCAÇÃO}

ISSN: 2526-849X

Muitos discursos que circulavam no interior dos próprios grupos de congada observados, assentavam-se sob uma perspectiva normativa e maniqueísta no que tange a religião. Dito de outra maneira, são compreensões reduzidas de análises tecidas pelos congadeiros que se limitam a dimensão binária: boa ou má; se pode ser dita ou não; se verdadeira ou falsa. Por efeito disso as práticas religiosas subalternizadas permanecem submetidas à clandestinidade, conforme glosa uma entrevistada:

[...] não interfere porque na festa a nossa devoção é a São Benedito e Nossa Senhora do Rosário, então uma coisa não mistura com a outra, então cê não pode vir aqui no meu grupo e botar a sua, o seu pensamento, sendo que o pensamento de todos é um só, então cê não pode mudar, então a pessoa tem que saber se o seu lugar mesmo se for de umbanda (Rosário).

"Saber o seu lugar" é permanecer "da porta pra dentro", realizando seus ritos e suas crenças no "particular" pelo fato de serem condenados socialmente. Essas formas de silenciamento e exclusão da religiosidade negra ocorridas no âmbito da congada evidenciou a efetiva colonização dos enunciados que se misturaram e se amalgamaram nos interstícios da trama social sem que, na maioria das vezes, fossem percebidos.

O intrigante de toda essa conjuntura aqui exposta se refere ao fato de que, embora a Congada tenha encontrado "morada" junto às irmandades católicas, o que por sua vez, denota algumas conquistas (em âmbito cultural/social) na esfera da legitimidade religiosa. Por um lado, as festividades congadeiras reverenciam os santos católicos, os quais são nomeados e considerados como "universais". Por outro, não foi percebido entre os depoentes que essa a universalidade do catolicismo ${ }^{15}$ foi algo construído e urdido historicamente, tal como sua sacralidade por suposto legítima. De todo modo, a despeito disso, inscreve-se nessa relação à conservação da congada e seu patrimônio cultural.

\section{A guisa da conclusão}

Ao longo das seções que integraram este artigo, situamos a congada na qualidade de patrimônio cultural imaterial da humanidade ao considerarmos a amplitude de tal conceito, inscrito sob diferentes expressões humanas.

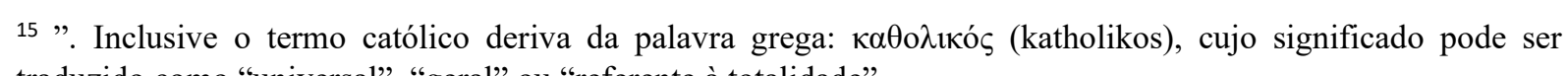
traduzido como "universal", "geral" ou "referente à totalidade". 
Em razão da complexidade de aspectos que circundam o universo congadeiro, distintas ciências (humanas e sociais) têm-se inclinado a investigá-lo, apesar disso, no campo da Educação são escassas as pesquisas que cotejem especificamente as relações formativas (entre ensino e aprendizado) suscitadas na e por intermédio da Congada. Nesse contexto, Costa (2020) figura como uma espécie de "estrela solitária" que, por sua vez, justifica a relevância da nossa iniciativa científica. O que chama mais atenção é que a autora sinaliza quanto à imperativa necessidade de transcendência do entendimento do conceito de Educação para afora dos espaços de escolarização formal.

Ousamos dizer que há no interior da expressão cultural congadeira uma gramática própria, um dialeto idiossincrático ainda pouco estudado, por efeito conhecido, cujo este estudo não foi capaz de retratar.

Consideramos que em termos de estrutura metodológica, houve assertividade tanto na acepção qualitativa, uma vez que nos permitiu certa liberdade e interação junto ao espaço e os pesquisados/as, quanto em relação aos recursos utilizados para erigir os dados. Compete-nos informar, além disso, que o delineamento aqui exposto representa uma das muitas "janelas" epistêmicas cuja investigação engendrou, sendo que outras comporão trabalhos póstumos. Quem sabe uma limitação metodológica tenha sido o tempo (apenas um ano e três meses para o desenvolvimento do estudo), ao passo que, caso houve uma liberdade em relação ao tempo e com isso pudéssemos acompanhar mais de uma edição da festa da congada de Lambari/MG, por exemplo, decerto a produção de materiais empíricos se ampliaria, muito embora a quantidade coleta fora expressiva.

Apesar do trabalho não possuir uma conotação histórica em termos epistemológicos, isto é, recorrer a análises documentais, tampouco ter como foco a produção de fontes históricas a partir dos depoimentos, seus desdobramentos operam nessa direção. Seja porque demonstrou a escassez de registros documentais sobre os ternos em tempos pretéritos, ou mesmo pelo fato de ter produzido um acervo de narrativas importantes que compõem um registro da história da congada em Lambari contada pelos seus principais praticantes.

Todavia, pode-se afiançar que o apogeu da prerrogativa histórica incidida pelo trabalho, refere-se ao fato de que embora a Congada tenha encontrado integração junto às irmandades católicas, sob certa admissão da comunidade africana em terras brasileiras, por certo denotou algumas oportunidades. Contudo, na esfera da legitimidade religiosa constatouse a importância da matriz originária banta, marcada pelo apreço à ancestralidade e o sagrado. 
Os depoentes ratificam essa universalidade do catolicismo, sem que houvesse (algum nível de) conscientização que se trata de algo construído e urdido historicamente, tal como sua sacralidade por suposto legítima. De todo modo, apesar disso, trata-se de uma estratégia para preservar a Congada e seu patrimônio cultural imaterial.

No que concerne as descobertas investigativas sobre as experiências formativas atinentes à Congada, verificamos a inexistência de um espaço-tempo predefinido para que o ensino e a aprendizagem acontecessem. Essa é uma constatação intrigante para os estudos sobre as congadas se considerarmos que há uma particularidade tradicional de transmissibilidade oral de saberes, rituais e convenções. Na maioria dos casos, o ensino da congada se assenta numa perspectiva empirista, na qual a aprendizagem do sujeito ocorreria externo a ele, sem que a sua atividade endógena (estrutura cognitiva) seja sequer mobilizada (BECKER, 1993).

A tradição oral africana que sustenta a perspectiva empirista de ensino foi deslocada nessa pesquisa, uma vez que houve um processo de ressignificação em relação aos modos de ensinar e aprender os saberes congadeiros. Já que alguns depoentes afirmaram ter aprendido agindo sobre o objeto de conhecimento, enquanto que outros apenas observando. Trata-se, portanto, de um ponto de vista que se distancia, em partes, da acepção empirista de ensino, aproximando-se de um sentido mais interacionista. Afirmamos isso porque os processos ocorreram de modo mais autônomo, intuitivo e exploratório em relação ao mundo congadeiro e suas relações. Embora termos verificado também, a presença do ensino transmitido linearmente (empirista), sobretudo, quando uma das depoentes fez referência que aprendeu com outro praticante. Entretanto, em menor escala, diferindo da centralidade tradicional referente à transmissibilidade oral.

Ainda nessa esteira, identificamos que houve consenso entre os depoentes sobre as alterações sofridas nos métodos de ensino e nos desejos de aprendizagem dos jovens no mundo contemporâneo. Os depoentes compararam o contexto atual com o momento que aprenderam (o patrimônio cultural da congada) na juventude, seja pela forma sobre a qual os mais velhos ensinavam ou em relação ao ethos comunitário congadeiro.

Um aspecto consensual dessa mudança se refere à falta de interesse sistemático por boa parte dos aprendizes, apesar de evidenciarem o empenho de alguns poucos. Neste ponto, nossa pesquisa sinaliza para necessidade de novos estudos cujo teor se aprofunde nessa questão do desinteresse dos praticantes mais jovens. Apesar de não tê-los ouvidos, os 


\section{OO DEVIR EDUCAÇÃO}

ISSN: 2526-849X

depoentes que tentam ensiná-los arriscam algumas causas para tal fenômeno, uma delas diz respeito à falta de embasamento para efetivação do ato. Além disso, mencionam a mudança de abordagem no que tange ao controle disciplinar dos envolvidos e o consequente respeito à hierarquia e as autoridades (ethos).

Em outra instância, os depoentes aludiram à questão dos aparatos tecnológicos, por efeito deles os jovens preterem os rituais da congada, uma situação que preocupa os ternos de modo geral. Outro aspecto suscitado por eles se refere ao descrédito dos saberes congadeiros "veteranos", advindos da longa experiência que possuem e que se empenham para apresentar aos neófitos.

Conscientes dessa adversidade que envolve o ensino, os mais velhos buscam estratégias para enfrentar a referida situação, um exemplo disso se materializa na flexibilização das regras de acesso aos instrumentos musicais. Tradicionalmente apenas tocaria o tambor, o dançante que já estivesse um tempo "no cordão" e já soubesse tocar pandeiro, reco-reco e agogô.

Outro fato demonstrado acerca dos congadeiros iniciantes fora o descompasso entre o desejo de ensinar (tradicional e empirista) e a expectativa de aprender dos mais novos. Expectativa essa inclinada às estratégias mais autônomas, intuitivas e exploratórias em relação ao tambor e seus componentes, tal como predominou quando os pequenos foram iniciados na Congada. Curiosamente, a questão do acesso ao tambor coloca em cena a musicalidade e uma vontade unívoca de tocá-lo, independentemente da dimensão sagrada que ele possa representar. Quiçá, o tambor, denote uma espécie de intersecção geracional do universo congadeiro.

Finalmente, destaca-se que a pesquisa realizada trata de uma realidade específica e não possui a finalidade de explicar um conjunto mais amplo de relações. No limite, pode-se trabalhar com a ideia de figurar na qualidade de um caminho heurístico para a realização de outras investigações científicas relativas ao tema, algumas, inclusive, explicitadas no próprio texto. Apesar dos limites, espera-se que este estudo lance rebento sobre as implicações formativas na e por intermédio da Congada, além de redimensionar a relevância do patrimônio cultural imaterial que ela consiste.

\section{Referências}


ANDRADE, Paula Deporte de; COSTA, Marisa Vorraber. Usos e possibilidades do conceito de pedagogias culturais nas pesquisas em estudos culturais em educação. Textura, v.17 n.34 p.48-63, Canoas/RS, mai./ago. 2015.

ANDRÉ, Marli. O que é um estudo de caso qualitativo em educação? Revista da FAEEBA Educação e Contemporaneidade, Salvador, v. 22, n. 40, p. 95-103, jul./dez. 2013.

BECKER, Fernando. Epistemologia do professor: o cotidiano da escola. Petrópolis: Editora Vozes, 1993.

BODGAN, R. \& BIKLEN, S. K. Investigação qualitativa em educação. Uma introdução à teoria e aos métodos. Porto: Porto Editora, 1994.

BONDIA, Jorge Larrosa. Notas sobre a experiência e o saber de experiência. Rev. Bras. Educ., Rio de Janeiro, n. 19, p. 20-28, Apr. 2002. Available from <http://www.scielo.br/scielo.php?script=sci_arttext\&pid=S1413-

24782002000100003\&lng=en\&nrm=iso $>\quad$ access $\quad$ on $\quad 25$ Apr. 2020. https://doi.org/10.1590/S1413-24782002000100003.

BRANDÃO, Carlos Rodrigues. Educação popular. São Paulo: Brasiliense, 1985.

CAPUTO, Stela Guedes. Educação nos terreiros: e como a escola se relaciona com crianças de candomblé. 1.ed. Rio de Janeiro: Pallas, 2012

CARMO, Luiz Carlos do. \& MENDONÇA. Marcelo Rodrigues (org). As congadas de Catalão: As relações, os sentidos e valores de uma tradição centenária. Catalão: UFG, 2008.

CHAUI, Marilena. A universidade pública sob nova perspectiva. Rev. Bras. Educ., Rio de Janeiro, n. 24, p. 5-15, Dec. 2003. Available from $<$ http://www.scielo.br/scielo.php?script=sci_arttext\&pid=S1413-

24782003000300002\&lng=en\&nrm=iso>. access on 25 Apr. 2020. https://doi.org/10.1590/S1413-24782003000300002.

COSTA, Aline Guerra da. Pedagogias da congada no contexto de produção das identidades, diferenças, territórios e saberes em Lambari - MG. (Dissertação de Mestrado em Educação). Universidade Federal de Lavras - Minas Gerais, 2020.

COSTA, Patrícia Trindade Maranhão. As raízes da congada: a renovação do presente pelos filhos do rosário. 2006. 241f. Tese (Doutorado em Antropologia Social)-Universidade de Brasília, Brasília, 2006.

COTA, Luis Gustavo Santos. Ave, libertas: abolicionismos e luta pela liberdade em Minas Gerais na última década da escravidão. Tese (Doutorado) - Universidade Federal Fluminense, 2013.

CUSTÓDIO SOBRINHO, Juliano. Sobre um tempo de incertezas: o processo da abolição e os significados da liberdade em Minas Gerais (1880-1888). Curitiba: Ed. CRV, 2018. 
DAMASCENA, Adriane Álvaro. Os jovens, a congada e a cidade: percursos e identidades de jovens congadeiros em Goiânia, Goiás. (Tese de Doutorado em Geografia). Universidade Federal de Goiás. Goiás, 2012.

DAVIS, Angela. Mulheres, raça e classe. Tradução de Heci Regina Candiani. 1.ed. São Paulo: Boitempo, 2016. Não paginado.

DELFINO, L. L. O Rosário dos Irmãos Escravos e Libertos: Fronteiras, Identidades e Representações do Viver e Morrer na Diáspora Atlântica. Freguesia do Pilar-São João Del-Rei (1782-1850). Tese (Doutorado em História) - Universidade Federal de Juiz de Fora, Juiz de Fora, 2015.

DENZIN, N. K; LINCOLN, Y. S. Handbook of qualitative research. 2nd. ed. Thousand Oaks: Sage, 2000.

FONSECA, Maria Cecília Londres et al. Celebrações e Saberes da cultura popular: pesquisa, inventário, crítica, perspectivas. Série Encontros e Estudos. Vol. 5. Rio de Janeiro: CNFCP/Funarte/Iphan, 2004.

JESUS JUNIOR, Audauto Garcia de. Estudos sobre branquitude e branqueamento no Brasil. Psico-USF (Impr.), Itatiba, v. 8, n. 2, p. 215-216, Dec. 2003.

HAGUETTE, André. Resenha de Metodologias qualitativas na Sociologia, de Teresa Maria Frota Haguette. Revista Brasileira de Estudos Pedagógicos. Brasília, v.75, n. 179/180/181, p. 373 394, jan/dez 1994.

HAMPATÉ-BÂ, Amadou. A tradição viva. In: História Geral da África, I: Metodologia e Pré-história da África. Joseph Ki-Zerbo (org). 2.ed.rev. Brasília: UNESCO, 2010. (pp.167 212).

HEYWOOD, Linda M. (org.). Diáspora negra no Brasil. 2.ed. São Paulo: Contexto, 2012.

KISHIMOTO, Alexandre, TRONCARELLI, Maria Cristina, DIAS, Paulo Anderson. O Reinado da Irmandade de Nossa Senhora do Rosário do Jatobá. São Paulo: Cachuera!, 2015, p. 15-16.

LE COMTE, M.; MILLROY, W.; PREISSLE, J. (Ed.). The handbook of qualitative research in education. San Diego: Academic, 1992.

LIMA-FERREIRA, S. DE; MAHFOUD, M.; SILVA, M. V. Trajetórias coletivas de congadeiros. Memorandum: Memória e História em Psicologia, v. 20, p. 177-200, 18 abr. 2011 .

LINS, Ivan. Novo Tempo. Direção de Produção: Renato Corrêa. São Paulo: EMI, 2004. 1 CD (45 min) Composição: Ivan Lins / Vitor Martins. 
LUDKE, Menga. e ANDRÉ, Marli. E. D. A. Pesquisa em educação: abordagens qualitativas. São Paulo, EPU, 1986.

MARTINS, Leda Maria. Afrografias da Memória: o reinado do rosário do jatobá. São Paulo: Perspectiva, 1997.

MELlO E SOUZA, Marina de. Reis Negros no Brasil Escravista. História da Festa de Coroação de Rei Congo. Belo Horizonte: Editora UFMG, 2002.

MONTEIRO, Lívia Nascimento. "A Congada é do mundo e da raça negra": memórias da escravidão e da liberdade nas festas de Congada e Moçambique de Piedade do Rio Grande-MG (1873-2015). Tese (Doutorado) - Universidade Federal Fluminense, 2016.

NASCIMENTO, Claudia Bibas do. Múltiplos olhares sobre a presença negra na Pala Paraná - História e arqueologia (séculos XIX e XX). 2009 118f. Dissertação (mestrado em História). Pontifícia Universidade Católica do Rio Grande do Sul. Porto Alegre, 2009.

OTTO, Rudolf. O Sagrado, Lisboa: Edições 70, 1992.

PELÚCIO, Larissa. Apresentação do Dossiê Saberes Subalternos. Dossiê Saberes Subalternos. In: Revista Contemporânea, v. 2, n. 2 (p. 303-307), Jul.-Dez. 2012a.

Subalterno quem, cara pálida? Apontamentos às margens sobre pós-colonialismos, feminismos e estudos queer. Dossiê Saberes Subalternos. In: Revista Contemporânea, v. 2, n. 2 (p. 395-418), Jul.-Dez. 2012 b.

RUFINO, Luiz. Pedagogia das Encruzilhadas. Rio de Janeiro: Mórula Editorial, 2019.

SAMPIERI, Roberto Hernández; COLLADO, Carlos Fernández, LUCIO, Maria del Pilar Baptista. Metodologia de Pesquisa. Porto Alegre: Penso, 2013.

SILVA, Daniel Albergaria. Festas de guardas, ternos e nações: a coroação de reis congos e a devoção à Nossa Senhora do Rosário. (Tese de Doutorado em Ciências Sociais). Universidade Federal de Juiz de Fora. Juiz de Fora, 2016.

SILVA, Francislei Lima da. Os monumentos da água no Brasil. Pavilhões, fontes e chafarizes nas estâncias sul mineiras (1880-1925). (Dissertação de Mestrado em História). Universidade Federal de Juiz de Fora - Minas Gerais, 2011.

SILVA, Luiz Geraldo. Religião e identidade étnica: africanos, crioulos e irmandades na américa portuguesa. Cahiers des Amériques latines [Online], 44|2003, posto online no dia 11 agosto 2017, consultado o 23 abril 2020. URL : http://journals.openedition.org/cal/7410 ; DOI : https://doi.org/10.4000/cal.7410.

SLENES, Robert W. Os Múltiplos Porcos e Diamantes: A Economia Escrava de Minas Gerais no Século XIX. In: Estudos Econômicos. São Paulo, V.18, nº 3, 1988, p.449-495. 
SOUZA, Marina de Mello. Reis negros no Brasil escravista: história da festa de coroação de Rei Congo. Belo Horizonte. Editora UFMG, 2002.

SOUZA, Tatiane Pereira. Permanências Africanas no Congado Brasileiro. Tese de Doutorado em Ciências Sociais). Unesp/Araraquara, 2018.

VIDICH, A. J.; LYMAN, S. M. Qualitative methods: Their history in sociology and antropology. In: DENZIN, N. K.; LINCOLN, Y. S. (Ed.). Handbook of qualitative research. 2nd ed. Thousand Oaks: Sage, 2000. p. 37-84. 